\title{
Estimasi Tinggi Gelombang Laut di Perairan Pantai Kijing Kabupaten Mempawah Kalimantan Barat

\author{
Lingga Permata Sari ${ }^{*}{ }^{*}$ Muliadi $^{a}$, Risko $^{b}$
}

\author{
Prodi Geofisika ${ }^{a}$, Prodi Ilmu Kelautan ${ }^{b}$ FMIPA Universitas Tanjungpura, \\ Jalan Dr. Prof. Hadari Nawawi Pontianak Indonesia \\ *Email : Linggapermata9@gmail.com
}

\begin{abstract}
Abstrak
Penelitian ini dilakukan untuk mengestimasi tinggi gelombang laut menggunakan Metode Wilson dan distribusi Weibull dengan variasi empat musim. Hasil dari penelitian ini menunjukkan bahwa dalam empat musim, arah angin dominan berasal dari Utara, Barat Laut, Barat Daya dan Selatan dengan kecepatan angin maksimum 4,61 m/s pada musim barat dan kecepatan minimum 0,90 m/s pada musim Timur. Fetch efektif terpanjang terjadi pada musim Peralihan II dari arah Barat Daya sejauh $124.128 \mathrm{~m}$. Tinggi gelombang laut maksimum dengan metode Wilson terjadi pada pada musim barat yaitu 0,36 m sedangkan tinggi gelombang minimum terjadi pada musim Peralihan I sebesar 0,02 m. Periode gelombang laut maksimum terjadi pada Musim Timur sebesar 4,66 detik dan periode gelombang laut minimum terjadi pada musim Peralihan I yaitu 1.75 detik. Tinggi maksimum gelombang laut jangka panjang terjadi pada musim barat dengan periode 5 tahun sebesar $0,39 \mathrm{~m}$ sedangkan tinggi gelombang minimum terjadi pada musim peralihan I yaitu $0,05 \mathrm{~m}$ pada periode 1 tahun.
\end{abstract}

Kata Kunci: Angin, Fetch, Gelombang, Periode Ulang, Pantai Kijing

\section{Latar Belakang}

Kabupaten Mempawah secara geografis terletak di koordinat $0,5^{\circ} \mathrm{LU}$ dan $108,875^{\circ} \mathrm{BT}$ dengan luas wilayah mencapai $1.276,09 \mathrm{~km}^{2}$. Saat ini pemerintah setempat gencar melakukan pembangunan dari berbagai sektor, diantaranya yaitu infrastruktur, pertanian, pendidikan, kesehatan hingga fasilitas umum. Salah satu proyek besar yang sedang dibangun yaitu rancangan pembangunan pelabuhan bertaraf internasional yang terletak di kawasan Pantai Kijing Kabupaten Mempawah.

Pelabuhan Internasional di Pantai Kijing Kabupaten Mempawah ini memiliki peran penting untuk melayani rute alur pelayaran antar negara, antar pulau maupun antar daerah, serta untuk membuka kegiatan ekonomi secara lebih luas di dunia Internasional. Kondisi pasang surut di perairan Pantai Kijing memiliki ketinggian muka air rata-rata $156 \mathrm{~cm}$ dengan kecepatan arus maksimum $1 \mathrm{~m} / \mathrm{s}$ dengan tinggi dan periode gelombang maksimum masing - masing adalah 1,35 $\mathrm{m}$ dan 5,13 s [1]. Pelabuhan yang dibangun akan ditingkatkan fungsinya agar dapat memberikan pelayanan terhadap seluruh pengguna jasa transportasi pelabuhan, dalam hal ini sangat penting mengetahui kondisi tinggi gelombang laut untuk jangka waktu yang panjang sebagai informasi rancangan pelabuhan dan kelanjutan dari kegiatan-kegiatan di pelabuhan itu sendiri.

Analisis gelombang laut jangka panjang menerapkan teori distribusi probabilitas untuk mengetahui parameter gelombang laut selama beberapa tahun [2]. Berikut beberapa penelitian terkait tinggi gelombang laut jangka panjang; Putri [3] melakukan penelitian tentang analisis statsitik gelombang laut yang di bangkitkan oleh angin dan menyimpulkan bahwa, tinggi gelombang laut maksimum dari perhitungan periode ulang tertentu 200 tahunan sebesar 5,04 m. Selanjutnya Supiyati et al. [4] melakukan analisis peramalan tinggi gelombang laut menggunakan periode ulang di laut dalam dan laut dangkal, tinggi gelombang yang terjadi selama sepuluh tahun di laut dalam yaitu $<3 \mathrm{~m}$ dan di laut dangkal, tinggi gelombang 0,3<0,4 m. Setiyawan et al. [5] melakukan penelitian tentang analisis peramalan tinggi gelombang laut dengan periode ulang menggunakan metode distribusi Weibull. Untuk mengetahui ketinggian gelombang yang akan digunakan dalam perencanaan bangunan pengaman pantai. Tinggi gelombang maksimum hasil perhitungan metode Weibull yaitu 0,236 m pada periode 200 tahun.

Berdasarkan penelitian di atas, diketahui bahwa semakin meningkat periode ulang maka nilai gelombang laut akan semakin tinggi. Sangat penting untuk mengetahui tinggi gelombang laut dalam jangka waktu yang panjang, tetapi informasi gelombang laut sulit untuk didapatkan, karena memerlukan waktu yang lama dan menghabiskan biaya yang cukup mahal. Oleh karena itu untuk mengetahui tinggi gelombang laut untuk jangka waktu yang panjang penelitian tentang Estimasi Tinggi Gelombang Laut di Perairan Pantai Kijing Kalimantan Barat dilakukan. 


\section{Metodologi}

Penelitian ini dilakukan di Perairan Pantai Kijing Sungai Kunyit Kabupaten Mempawah yang merupakan lokasi pembangunan pelabuhan bertaraf Internasional. Secara geografis daerah tersebut terletak di $0,5^{\circ} \mathrm{LU}$ dan $108,875^{\circ} \mathrm{BT}$.

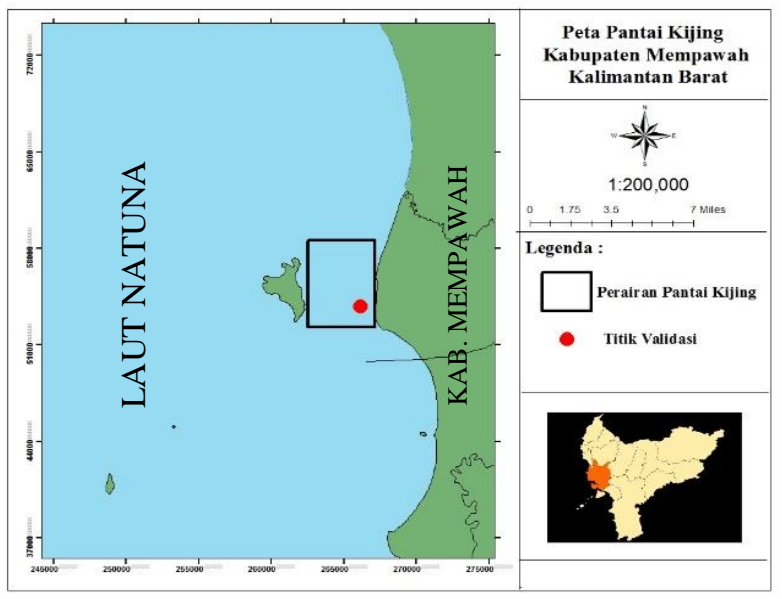

Gambar 2.1 Lokasi Penelitian

Pada penelitian ini data yang digunakan yaitu data primer dan data skunder. Data primer merupakan data dari tinggi gelombang laut yang diukur langsung dilokasi penelitian, sedangkan data sekunder merupakan data arah dan kecepatan angin yang di unduh dari web ECMWF (Europian Center For Medium-Range Weather Forecasts). Dalam penelitian ini digunakan data angin harian dalam satu bulan perpuncak musim, dengan panjang data 10 tahun dari tahu 2008 2017. Data primer dari tinggi gelombang laut dikur langsung selama 3 hari, dalam rentang pembagian waktu 3 kali sehari yaitu pagi, siang dan sore. Titik pengamatan gelombang laut diambil sejauh $263 \mathrm{~m}$ dari garis pantai.

Estimasi tinggi gelombang laut jangka panjang pada penelitian ini dilakukan dalam dua tahap yaitu menetukan tinggi gelombang laut signifikan dengan Metode Wilson dan menentukan tinggi gelombang laut jangka panjang menggunakan Metode Weibull.

Untuk mencapai tujuan penelitian, ditentukan arah dan kecepatan angin serta panjang fetch effektif, agar dapat diketahui tinggi dan periode gelombang laut yang dibangkitkan oleh angin dengan Metode Wilson pada persamaan 1 dan 2. Tinggi gelombang laut yang dihitung menggunakan Metode Wilson diverifikasi dengan tinggi gelombang laut observasi untuk mendapatkan perbandingan error relatif.

Analisis tinggi gelombang laut jangka panjang diolah menggunakan Metode Distribusi Weibull yang dihitung dengan persamaan $3-5$.
Adapun persamaan yang diperlukan yaitu sebagai berikut:

Estimasi tinggi gelombang laut signifikan :

$$
\begin{aligned}
& H_{s}=\frac{0,3}{g}\left[1-\left\{1+0,004\left(\frac{g F}{U}\right)^{1 / 2}\right\}^{-2}\right] U^{2} \\
& T_{s}=6,23 \times 10^{-2}\left(U_{A} F\right)^{1 / 3}
\end{aligned}
$$

dimana $U$ merupakan kecepatan angin sedangkan $U_{A}$ adalah tegangan angin dan $F$ yaitu panjang fetch effekti, $H s$ adalah tinggi gelombang laut signifikan dan Ts adalah periode gelombang laut signifikan.

Fungsi Distribusi Probabilitas :

$P(H s \geq H s m)=-\frac{m-0,22-\frac{0,22}{\sqrt{\mathrm{k}}}}{\mathrm{N}_{\mathrm{T}}-0,2+\frac{0,23}{\sqrt{\mathrm{k}}}}$

$\mathrm{P}(H s \geq H s m)$ merupakan Probablititas tinggi gelombang representatif sedangkan $m$ adalah nomor urut tinggi gelombang laut signifikan, $N_{T}$ yaitu jumlah kejadian gelombang selama pencatatan atau banyaknya data gelombang dan $K$ adalah parameter bentuk, dalam penelitian ini dipakai k yaitu 0,75 .

Tinggi gelombang signifikan untuk berbagai periode ulang dihitung dari fungsi distribusi probabilitas:

$H_{s r}=\widehat{A} y_{r}+\widehat{B}$

dengan $y_{r}$ diberikan sebagai bentuk berikut:

$y_{r}=\left\{\ln \left(L T_{r}\right)\right\}^{1 / k}$

dimana $H_{s r}$ merupakan tinggi gelombang laut signifikan dengan periode ulang tertentu dan $y_{r}$ adalah distribusi frekuensi periode ulang (tahun) sedangkan $T_{r}$ adalah periode ulang atau tahun yang ditentukan, $K$ adalah panjang data dan $L$ merupakan rata - rata jumlah kejadian per tahun $\left(N_{T} / K\right)$. 


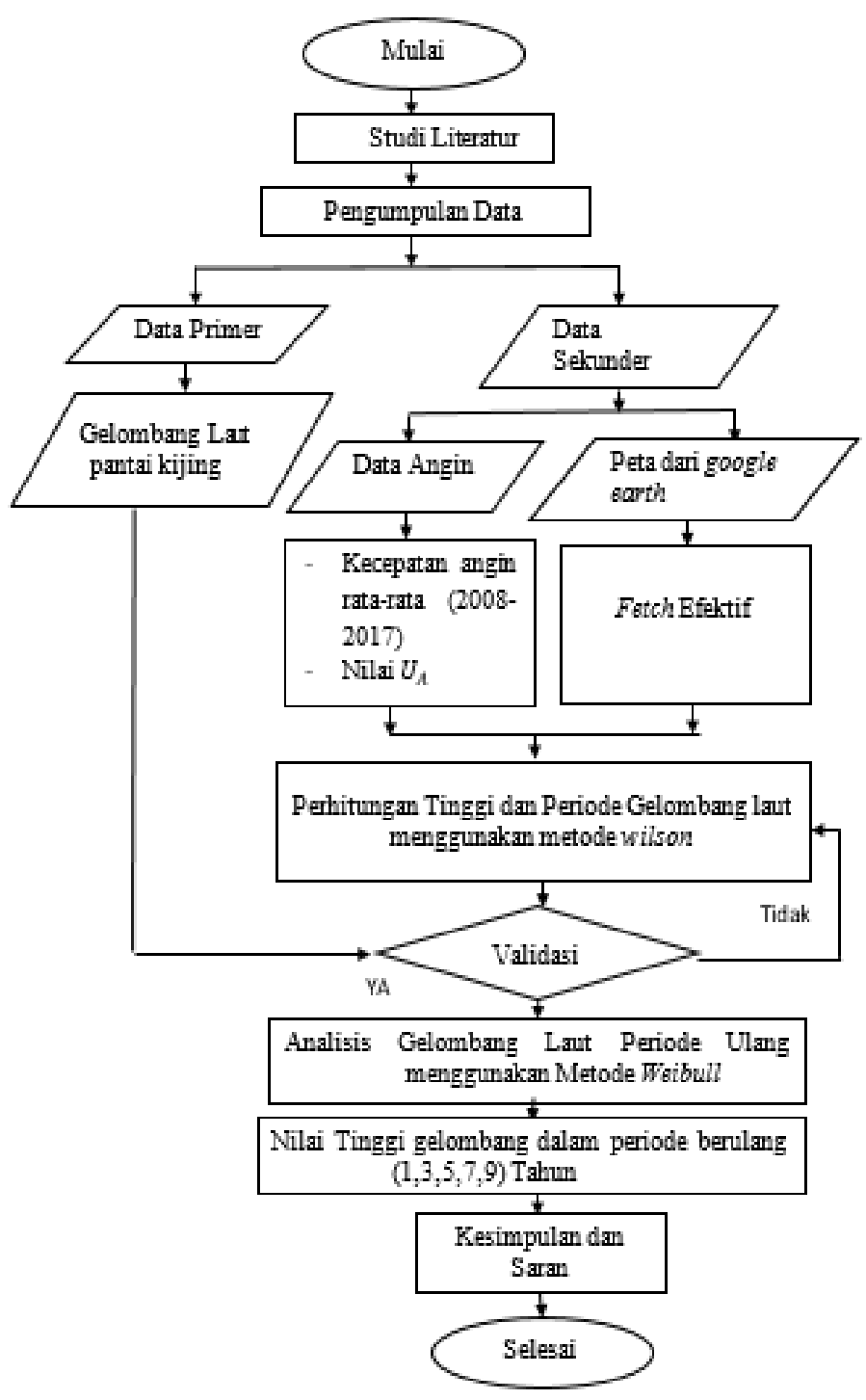

Gambar 2.2 Diagram Alir Penelitian

\section{Hasil dan Pembahasan}

\subsection{Distribusi Angin}

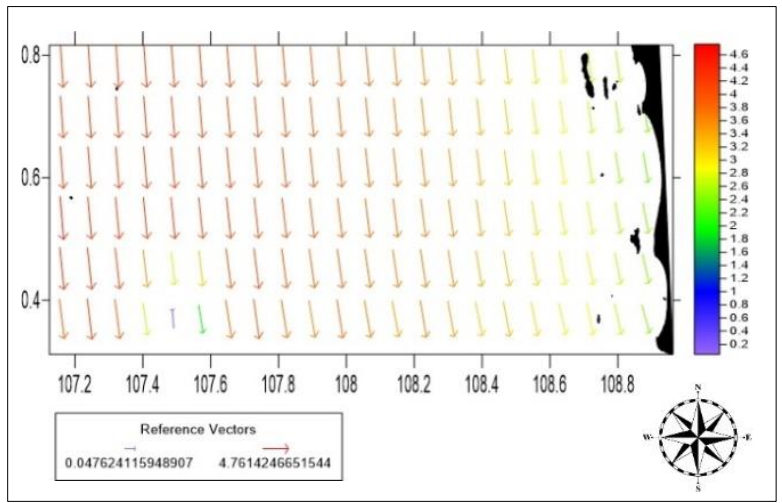

Gambar 3.1 Distribusi Angin Bulan Januari

Gambar 3.1 menunjukkan angin di bulan Januari berhembus dari arah Utara menuju selatan, sering disebut Musim Barat dengan kecepatan angin berkisar antara 0,04 -4,76 m/s

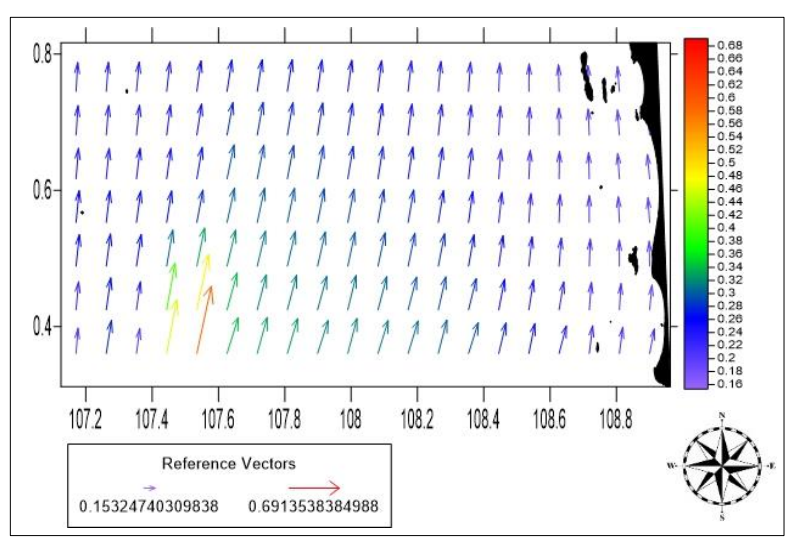

Gambar 3.2 Distribusi Angin Bulan April

Gambar 3.2 menunjukkan Musim Peralihan I yang terjadi pada bulan April, arah angin bervariatif berhembus dari Selatan dan Barat Daya menuju Utara dengan kecepatan angin antara $0,153-0,691 \mathrm{~m} / \mathrm{s}$.

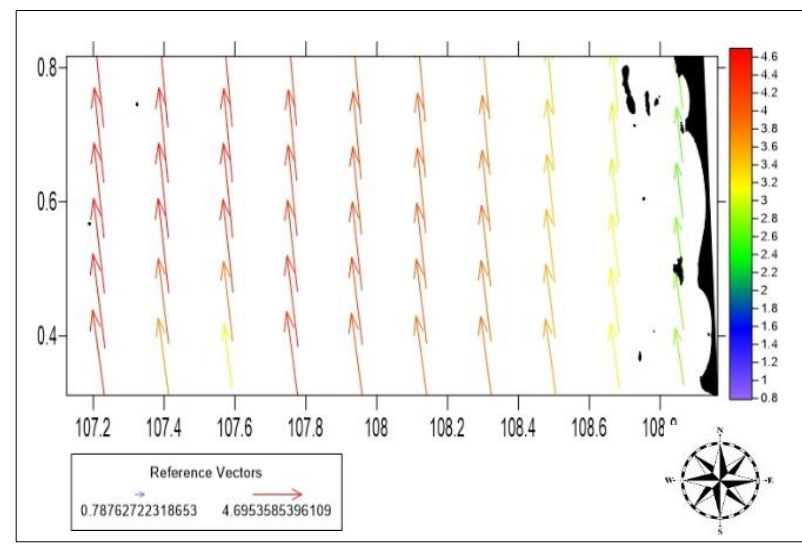

Gambar 3.3 Distribusi Angin Bulan Juli

Gambar 3.3 menunjukkan distribusi angin bulan Juli atau dikenal dengan Musim Timur, angin bertiup dari Tenggara menuju Utara dengan kecepatan berkisar antara 0,78 - 4,69 $\mathrm{m} / \mathrm{s}$.

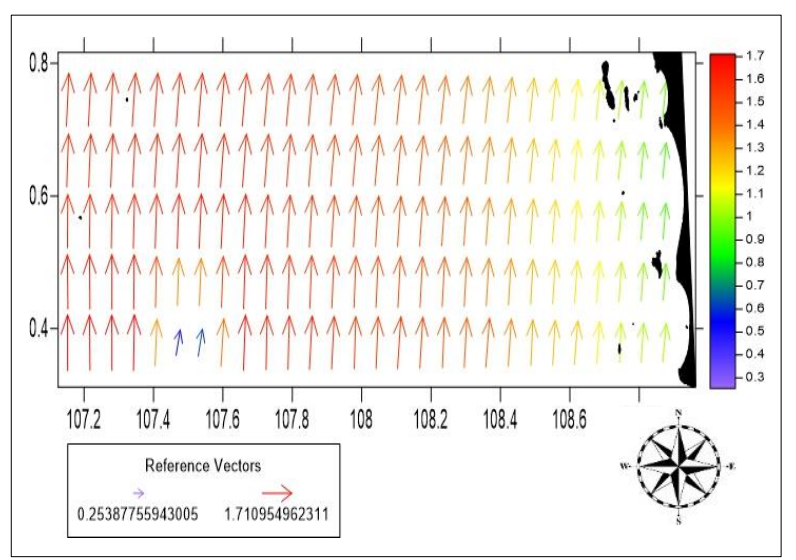

Gambar 3.4 Distribusi Angin Bulan Oktober 
Gambar 3.4 menunjukkan angin bulan Oktober lebih bervariatif berhembus dari Selatan dan Barat Daya menuju utara dengan kecepatan antara $0,25-1,71 \mathrm{~m} / \mathrm{s}$.

Dari hasil penelitian diatas dilihat bahwa, pada Musim Barat arah dominan angin berasal dari utara. Hal ini terjadi karena adanya gaya coriolis yang menyebabkan angin mengalami pembelokan arah. Begitupula dengan angin dominan pada bulan Juli, berasal dari arah selatan. Sedangkan bulan April dan Oktober, sering dikenal dengan Musim Peralihan I dan Musim Peralihan II, arah angin pada kedua musim ini sangat bervariatif, hal ini disebabkan karena, matahari bergerak melintasi wilayah khatulistiwa menyebabkan angin menjadi lemah dan arahnya tidak teratur, pada musim ini masih dipengaruhi oleh Musim Barat dan Musim Timur sehingga menyebabkan perubahan cuaca yang tidak menentu $[6 ; 7]$

\subsection{Fetch}

Fetch merupakan daerah utama pembentuk gelombang laut yang dibangkitkan oleh angin. Pada penelitian ini panjang fetch ditarik dari arah angin yang dominan. Adapun angin yang dominan di area penelitian ini yaitu Utara, Selatan, Barat Daya dan Barat laut.

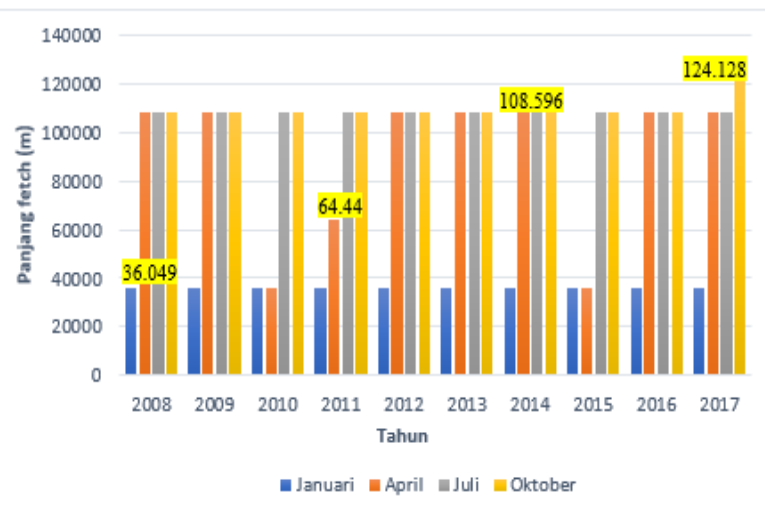

Gambar 3.5 Panjang Fetch Efektif

Pada gambar 3.5 dilihat bahwa fetch efektif terpanjang terjadi pada bulan Oktober 2017. Disebabkan karena pada bulan ini arah dominan angin berasal dari Barat Daya, panjang segmen fetch tidak dihalangi oleh rintangan atau daratan, sehingga membuat segmen fetch lebih panjang dari bulan lainnya.

Sedangkan pada bulan Januari panjang fetch relatif lebih pendek, dikarenakan arah dominan angin berasal dari Utara. Bagian Utara di pantai kijing banyak terdapat rintangan seperti pulaupulau, sehingga penarikan garis fetch berhenti sampai di batas pulau. Sehingga fetch lebih pendek dari bulan lainnya.

Pada bulan Juli panjang fetch relatif sama, tetapi lebih panjang dari fetch bulan Januari, karenakan arah dominan angin pada bulan ini berasal dari Selatan, pada arah selatan Pantai Kijing, terdapat lebih sedikit pulau sehingga panjang fetch pada bulan Juli lebih panjang dibandingkan bulan Januari.

Pada bulan April dan Oktober panjang fetch cendrung berubah-ubah, karena arah angin pada bulan ini relatif bervariasi. Arah angin dominan pada bulan April berasal dari Utara, Selatan dan Barat Laut. Sedangkan pada bulan Oktober arah angin dominan berasal dari Selatan dan Barat Laut, sehingga menyebabkan panjang fetch pada kedua bulan inipun cendrung bervariatif.

\section{3 . Verifikasi Data}

Data tinggi dan periode gelombang lapangan yang digunakan untuk verifikasi, diambil pada tanggal 20 Februari 2019 dengan tinggi gelombang sebesar $0.112 \mathrm{~m}$. dan periode gelombang 4.8148 detik.

Dari tabel 3.1 dapat dilihat bahwa hasil perhitungan $R E$ dari perhitungan antara pengukuran lapangan dan perkiraan sebesar $47.7 \%$ dan periode gelombang sebesar $42.18 \%$.

Tabel 3.1 Verifikasi tinggi dan periode gelombang

\begin{tabular}{ccc}
\hline Gelombang & Hs $(\mathrm{m})$ & Ts (detik) \\
\hline $\begin{array}{c}\text { Pengukuran } \\
\text { Lapangan }\end{array}$ & 0.11 & 4.81 \\
$\begin{array}{c}\text { Perkiraan } \\
\text { Gelombang }\end{array}$ & 0.16 & 2.78 \\
$\begin{array}{c}\text { Relatif Error } \\
(R E)\end{array}$ & $\mathbf{4 7 . 7 \%}$ & $\mathbf{4 2 . 1 8 \%}$ \\
\hline
\end{tabular}

nilai $R E$ kurang dari 50\% sehingga, perkiraan gelombang dapat digunakan untuk pengolahan gelombang tahap selanjutnya [8].

\subsection{Estimasi Tinggi dan periode Gelombang}

Perhitungan gelombang laut menggunakan metode wilson, dihitung dari tahun 2008 - 2017. Hasil perhitungan yang diperoleh berupa tinggi dan periode gelombang, dilihat pada gambar 3.6 dan 3.7.

Tinggi gelombang maksimum pada Bulan Januari terjadi tahun 2008 sebesar 0,36 m dengan periode gelombang 3,4355 detik dan kecepatan angin rata-rata sebesar 4,61 m/s arah dominan angin dari Utara. Sedangkan tinggi gelombang minimum pada bulan ini, terjadi pada tahun 2016 yaitu sebesar 0,08 m. dengan periode gelombang 2,393 detik dan kecepatan angin ratarata $0,90 \mathrm{~m} / \mathrm{s}$. periode gelombang laut pada bulan januari relatif lebih kecil dibandingkan bulan Juli. 


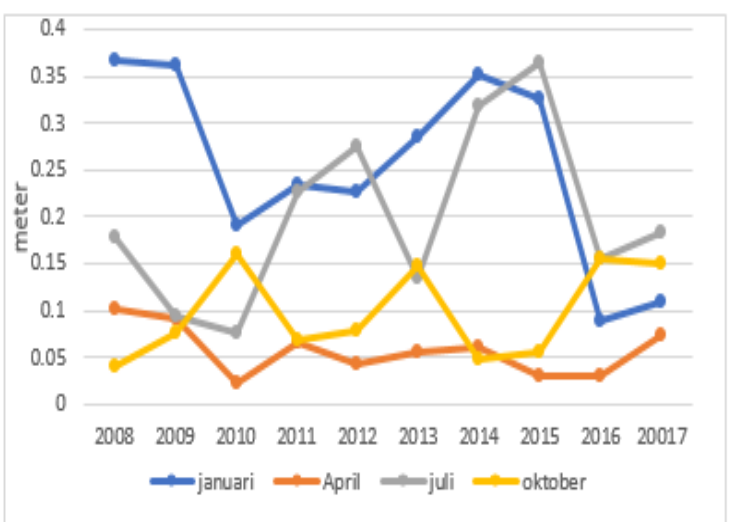

Gambar 3.6 Tinggi Gelombang Laut

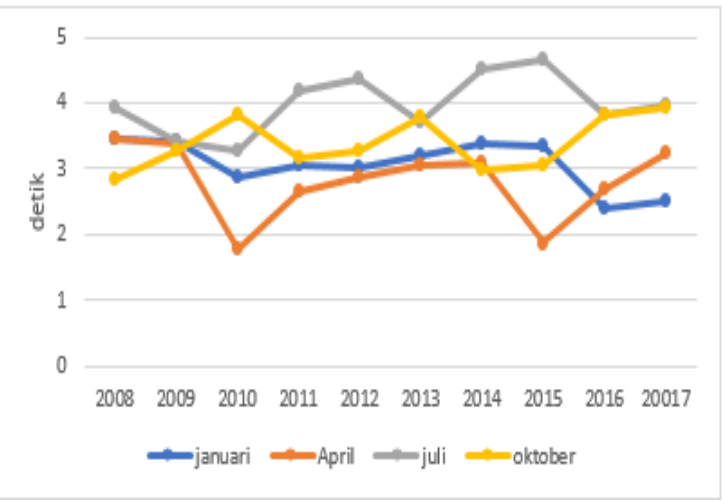

Gambar 3.7 Periode Gelombang Laut

Tinggi gelombang maksimum bulan April terjadi pada tahun 2008 sebesar 0,10 m dengan periode gelombang 3,45 detik. Tinggi gelombang minimum pada bulan ini terjadi pada tahun 2010 yaitu 0,02 $\mathrm{m}$. dengan periode gelombang 1,758 detik. Arah angin dominan pada bulan ini sangat bervariatif dari Utara, Selatan dan Barat Laut.

Pada bulan juli rata -rata tinggi gelombang laut lebih kecil dibanding bulan Januari, dan lebih tinggi dari bulan April dan Oktober, hal ini disebabkan karena angin yang berhembus pada bulan Juli lebih kuat dibandingkan bulan April dan Oktober. Arah angin dominan pada bulan juli berasal dari Selatan. Tinggi gelombang maksimum pada bulan ini terjadi pada tahun 2015 sebesar $0,36 \mathrm{~m}$. dengan periode gelombang 4,661 detik. Tinggi gelombang minimum terjadi pada tahun 2010 yaitu sebesar 0,07 m dengan periode gelombang 3,264 detik.

Oktober merupakan puncak musim peralihan II tinggi perkiraan gelombang pada bulan Oktober lebih kecil dibandingkan bulan Januari dan Juli tetapi lebih besar dari pada bulan April. Tinggi gelombang maksimum pada bulan ini terjadi pada tahun 2010 sebesar 0,15 m dengan periode gelombang 3,835 detik. Tinggi gelombang minimum terjadi pada tahun 2008 yaitu sebesar 0,04 $\mathrm{m}$ dengan periode gelombang 2,847 detik Kecepatan dan arah angin pada bulan oktober juga bervariatif seperti bulan April, arah angin dominan pada bulan ini berasal dari selatan dan barat daya.

Berdasarkan gaya pembangkitnya gelombang yang terbentuk merupakan gelombang yang dibangkitkan oleh angin, karena mempunyai periode signifikan sebesar tidak lebih dari 10 detik. Hal ini didukung oleh klasifikasi gelombang berdasarkan periode menurut munk [8] yang menyatakan gelombang yang dibangkitkan oleh angin mempunyai periode gelombang antara 1-10 detik.

\subsection{Estimasi Gelombang Periode Ulang}

Untuk melakukan estimasi tinggi gelombang signifikan periode ulang dalam penelitian ini menggunakan metode Weibull.

Probabilitas adalah peluang atau kemungkinan dari suatu kejadian terjadi atau tidak, dan seberapa besar kemungkinan kejadian tersebut berpeluang untuk terjadi. Sehingga didapat nilai probabilitas sebagai berikut :

Dari Tabel 3.2 kolom satu merupakan peringkat tinggi gelombang yang dihitung menggunakan metode Wilson, diurut dari data tinggi gelombang terbesar sampai terkecil. Kolom kedua merupakan probabilitas atau peluang kejadian, pada tabel di atas probabilitas berkisar antara $0-1$, dimana kemungkinan gelombang yang akan terjadi sebesar $94 \%$ dengan nilai probabilitas 0.94 dan kemungkinan terkecil gelombang akan terjadi sebesar 1,2\% dengan probabilitas 0,012. Kolom ketiga merupakan nilai dari distribusi probabilitas atau disebut Ym yang akan dihubungkan dengan distribusi frekuensi periode ulang atau Yr untuk mendapatkan nilai tinggi gelombang periode ulang.

Tabel 3.2 Probabilitas Gelombang

\begin{tabular}{ccc}
\hline Tahun & Probabilitas & Ym \\
\hline 1 & 0.94 & 2.15 \\
2 & 0.83 & 1.36 \\
3 & 0.73 & 0.98 \\
4 & 0.62 & 0.73 \\
5 & 0.51 & 0.54 \\
6 & 0.41 & 0.39 \\
7 & 0.30 & 0.27 \\
8 & 0.19 & 0.16 \\
9 & 0.09 & 0.073 \\
10 & 0.01 & 0.009 \\
\hline
\end{tabular}


Perkiraan gelombang periode ulang diolah berdasar puncank musim, sehingga didapat nilai tinggi gelombang periode ulang pada bulan Januari, April, Juli dan Oktober.

perkiraan tinggi gelombang dengan periode ulang tertentu dapat dilihat dari tabel 3.3 dan gambar 3.8 .

Tabel 3.3 Estimasi Tinggi Gelombang Laut Periode ulang

\begin{tabular}{cccccc}
\hline $\begin{array}{c}\text { Periode } \\
\text { Berulang }\end{array}$ & Yr & \multicolumn{5}{c}{ Hsr } \\
\cline { 3 - 6 } & & Januari & April & Juli & Oktober \\
\hline 1 & 0 & 0.16 & 0.03 & 0.10 & 0.05 \\
2 & & & & & \\
3 & 1.46 & 0.34 & 0.08 & 0.30 & 0.14 \\
4 & 2.14 & 0.43 & 0.11 & 0.40 & 0.19 \\
5 & 2.59 & 0.48 & 0.12 & 0.46 & 0.21 \\
& & & & & \\
& 2.92 & 0.52 & 0.14 & 0.50 & 0.23 \\
\hline
\end{tabular}

Tabel 3.3 merupakan hasil perhitungan estimasi tinggi gelombang laut periode ulang, dimana kolom satu merupakan periode ulang yang ditentukan, kolom kedua merupakan distribusi frekuensi dari periode ulang yang ditentukan dan kolom tiga merupakan hasil estimasi tinggi gelombang laut berdasarkan periode ulang pada bulan Januari, april, Juli dan Oktober. Untuk mendapatkan nilai tinggi gelombang berdasarkan periode ulang (Hsr), reduced variabel periode ulang (Yr) harus dihubungkan dengan reduced variabel dari probabilitas gelombang (Ym) dan konstanta gelombang laut yang dihitung menggunakan persamaan kuadrat terkecil, lalu tinggi gelombang laut diestimasikan menggunakan persamaan regresi linier.

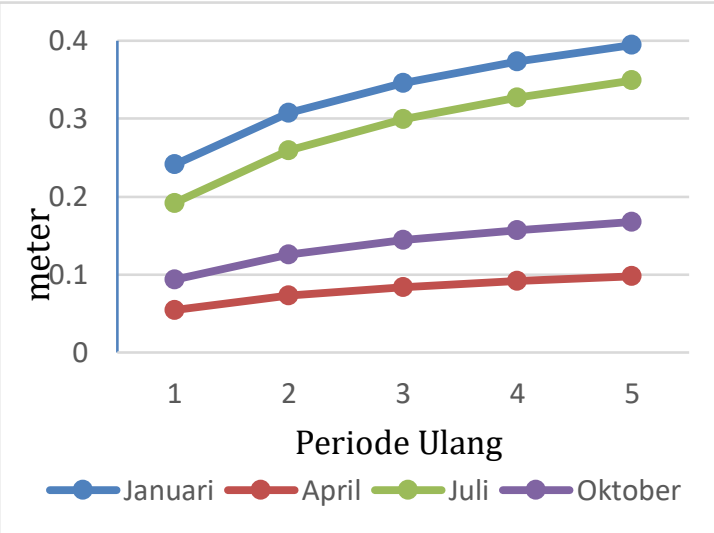

Gambar 3.8 Estimasi Tinggi Gelombang Laut Periode Ulang
Gambar 3.8 merupakan grafik hasil perhitungan gelombang laut periode ulang, sumbu y merupakan estimasi tinggi gelombang laut di Perairan Pantai Kijing sedangkan sumbu x adalah periode ulang yang ditentukan untuk mengestimasikan tinggi gelombang laut. Hasil perhitungan estimasi tinggi gelombang dengan periode ulang dapat dilihat dari grafik bahwa semakin tinggi periode berulang maka semakin besar pula tinggi gelombang.

Estimasi tinggi gelombang laut pada bulan januari dengan periode 1 tahun didapatkan nilai tinggi gelombang sebesar $0,24 \mathrm{~m}$ sedangkan nilai estimasi tinggi gelombang laut untuk periode 2 tahun yaitu $0,30 \mathrm{~m}$, nilai estimasi tinggi gelombang laut pada periode 3 tahun yaitu sebesar 0,34 $\mathrm{m}$ sedangkan estimasi tinggi gelombang laut periode 4 tahun memiliki tinggi gelombang sebesar $0,37 \mathrm{~m}$ dan perhitungan estimasi tinggi laut periode 5 tahun sebesar 0,39 $\mathrm{m}$. Tinggi gelombang periode ulang pada Musim Barat lebih besar dibandingkan dengan musim yang lainnya.

Estimasi tinggi gelombang periode ulang pada bulan April relatif jauh lebih kecil dibandingkan bulan Januari. Estimasi tinggi gelombang laut periode 1 tahun yaitu $0,05 \mathrm{~m}$, lalu untuk estimasi tinggi gelombang laut dengan periode 2 tahun memiliki nilai sebesar $0,07 \mathrm{~m}$ sedangkan pada periode 3 tahun estimasi tinggi gelombang yang didapat yaitu 0,08 m,estimasi tinggi gelombang laut dengan periode 4 tahun sebesar 0,09 $\mathrm{m}$ dan pada periode 5 tahun estimasi tinggi gelombang sebesar 0,09 m.

Tinggian gelombang laut signifikan periode ulang pada bulan Juli relatif lebih besar dibandingkan bulan April dan Oktober. Estimasi tinggi gelombang laut dengan periode ulang 1 tahun sebesar 0,19 m sedangkan untuk periode 2 tahun estimasi tinggi gelombang laut sebesar $0,26 \mathrm{~m}$, untuk nilai estimasi tinggi gelombang laut dengan periode 3 tahun sebesar 0,29 m, estimasi tinggi gelombang laut periode 4 tahun sebesar 0,32 $\mathrm{m}$ dan pada periode 5 tahun nilai estimasi tinggi gelombang sebesar $0,34 \mathrm{~m}$.

Tinggi gelombang periode ulang bulan Oktober memiliki nilai yang lebih kecil dibandingkan bulan Juli, tetapi lebih besar dibandingkan bulan April. Estimasi tinggi gelombang laut dengan periode 1 tahun memiliki nilai sebesar 0,09 m sedangkan periode 2 tahun estimasi tinggi gelombang yaitu $0,12 \mathrm{~m}$ untuk estimasi tinggi gelombang laut periode 3 tahun yaitu sebesar 0,14 m, nilai estimasi tinggi gelombang laut dengan periode 4 tahun yaitu sebesar $0,15 \mathrm{~m}$ dan untuk periode 5 tahun estimasi tinggi gelombang sebesar $0,16 \mathrm{~m}$. 


\section{Kesimpulan}

Bedasarkan hasil penelitian yang telah dilakukan dapat di simpulkan bahwa Kondisi kecepatan angin di Perairan Pantai Kijing berkisaran antara $0,90-4,76 \mathrm{~m} / \mathrm{s}$ sedangkan fetch efektif terpanjang terjadi pada Musim Peralihan II 2017, dengan panjang fetch 124.128 $\mathrm{m}$ dari arah Barat Daya. Tinggi gelombang laut maksimum yg diolah menggunakan metode Wilson terjadi pada Musim Barat yaitu 0,36 m sedangkan tinggi gelombang laut minimum terjadi pada Musim Peralihan I sebesar 0,02 m. Periode gelombang laut maksimum yang diolah menggunakan metode Wilson terjadi pada Musim Timur yaitu 4,66 detik dan periode minimum sebesar 1,75 detik. Tinggi maksimum gelombang laut jangka panjang terjadi pada Musim Barat, dengan periode 5 tahun yaitu 0,39 $\mathrm{m}$ dan tinggi minimum gelombang laut jangka panjang terjadi pada Musim Peralihan I sebesar $0,05 \mathrm{~m}$.

\section{Daftar Pustaka}

[1]. Rencana Induk Pelabuhan Pontianak Provinsi Kalimantan Barat, Lampiran Mentri Perhubungan Republik Indonesia, Jakarta, 2016.

[2]. Kamphius, J.W., Introduction to Coastal Engineering and Management $2^{\text {nd }}$ Edtion, World Scientific, Queen's University, Canada, 2010

[3]. Putri, M.D. dan Tarigan, M.P.A., Analisis Statistik Gelombang yang Dibangkitkan Oleh Angin Untuk Pelabuhan Belawan, Jurnal. Universitas. Sumatra. Utara., 6(1), 2017.

[4]. Supiyati., Analisis Peramalan Ketinggian Gelombang Laut dengan Periode Ulang Menggunakan Metode Gumbel Fisher Tippet - Tipe 1 Studi Kasus : Perairan Pulau Baai Bengkulu, Jurnal. Gradien., 4, 349-353, 2008.

[5]. Setiyawan.; Rusdin, A.; Adnyani, N., Analisis Peramalan, Ketinggian Gelombang Laut dengan Periose Ulang Menggunakan Metode Distribusi weibull ( Studi Kasus Pantai Lembasada Kabupaten Donggala), Insfrastruktur., 5, 38-50, 2015.

[6]. Utami, R.I.; Jumarang, M.I.; Apriansyah., Perhitungan Potensi Energi Angin di Kalimantan Barat, Prisma. Fisika., 6, 6569, 2018.

[7]. Mulyadi.; Jumarang, M.I.; Apriansyah., Variabilitas Tinggi dan Periode Gelombang Laut Signifikan di Selat Karimata, Positron., 5, 19-25,2015.
[8]. Agustino, 0.; Indra, B.P.; Aris, I., Penjalaran Transformasi Gelombang Diperairan Pelabuhan Tanjung Kelian Kabupaten Bangka Barat, Jurnal. Oceanografi., 3, 236 - 245, 2014. 